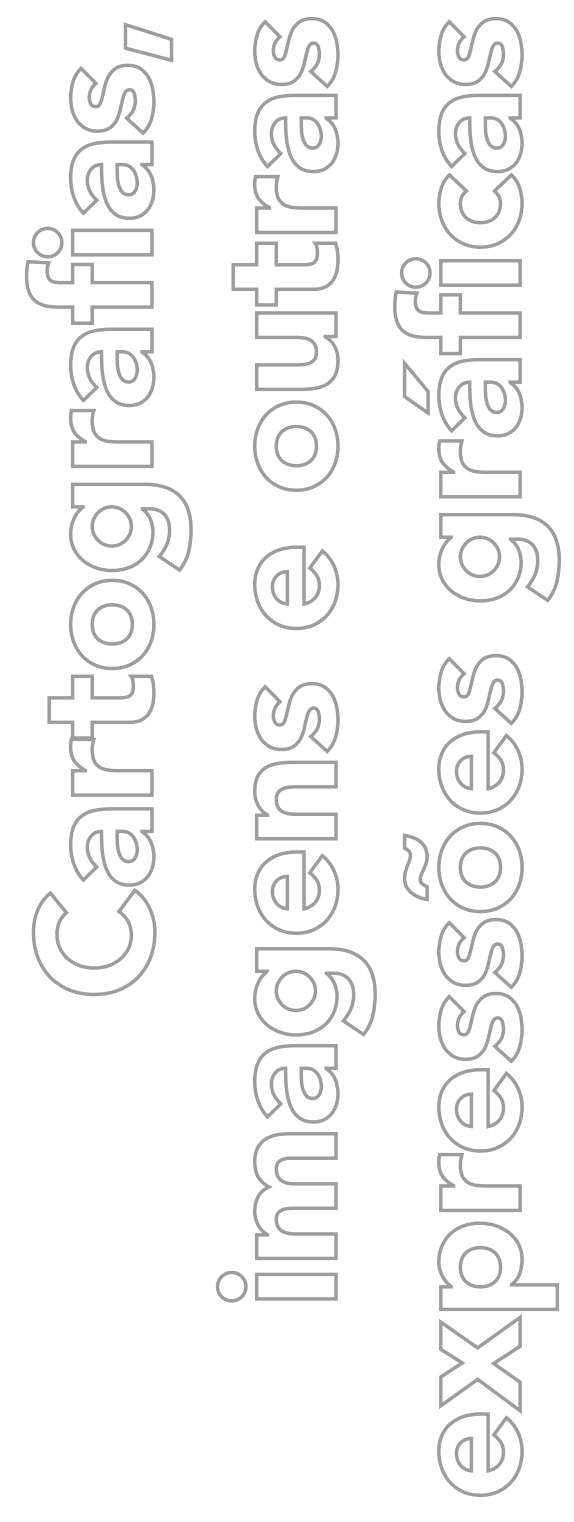

revista

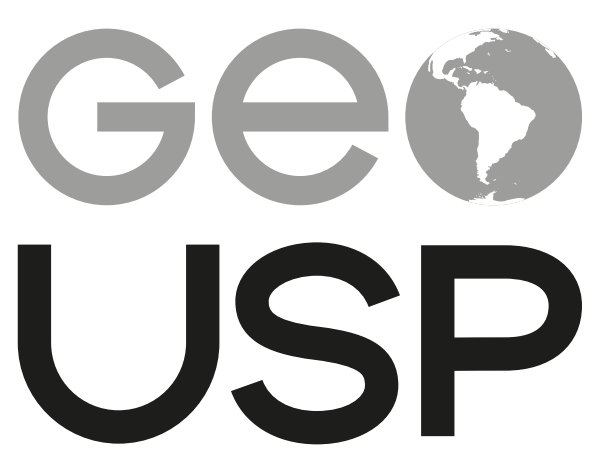

espaço e tempo

Volume $25 \bullet n^{\circ} 2(2021)$

ISSN 2179-0892
Expressões cartográficas da região das Guianas

\author{
Gutemberg de Vilhena Silva \\ Universidade Federal do Amapá. Colegiado de \\ Relações Internacionais. Macapá. Amapá. Brasil \\ bgeografo@gmail.com \\ (1) 0000-0002-4607-8634
}

e-175029

Como citar este artigo:

SILVA, G. V. Expressões cartográficas da região das Guianas. Geousp, v. 25, n. 2, e-175029, 2021, ISSN 2179-0892.

Disponível em: https://www.revistas.usp.br/geousp/article/ view/156773. doi: https://doi.org/10.11606/issn.2179-0892. geousp.2021.175029.

\section{(c) $\underset{\mathrm{By}}{\mathrm{By}}$}

Este artigo está licenciado sob a Creative Commons Attribution 4.0 Licence 


\title{
Expressões cartográficas da região das Guianas ${ }^{1}$
}

\section{Resumo}

A partir da metade do século XX, proliferaram estudos em diversos campos de conhecimento sobre a região das Guianas. Mesmo assim, até hoje há uma grande lacuna na atualização de cartografias temáticas que expliquem suas geografias. objetivo deste texto é tecer reflexões sobre a construção de cinco mapas que elaboramos para evidenciar aspectos do ordenamento territorial da região e, com isso, elucidar questões relevantes de seu passado e presente. Para compor os mapas e nossa argumentação, recorremos à revisão de literatura, à coleta e tabulação de dados primários (estatísticas) e ao trabalho de campo como balizas metodológicas.

Palavras-chave: Geografia Regional. Região das Guianas. Trabalho de campo. Cartografia.

\section{Cartographic expressions of the Guyana region}

\begin{abstract}
From the middle of the 20th century, there was a proliferation of studies in various fields of knowledge about the Guyana region. Even so, until today there is a big gap in updating thematic cartographies that explain their geographies. Our objective in this text is to outline reflections on the construction of 5 maps that we had elaborated to highlight aspects of the territorial ordering of that region and - with that - to elucidate relevant questions of the past and present of the Guyanas. To compose the maps and our arguments, we used literature review, the collection and tabulation of primary data (statistics) and fieldwork as methodological guidelines.
\end{abstract}

Keywords: Regional Geography. Guiana Region. Fieldwork. Cartography.

Este texto contou com o apoio da Universidade Federal do Amapá por meio do edital 0/010 Papesq/Unifap 2020, processo n. 23125.015080/2020-88, e do projeto financiado Estudos de Fronteira em Perspectiva Multidisciplinar e Multidimensional, processo n. 23125.020458/2018-10. 


\section{Expressions cartographiques de la région des Guyanes}

\section{Résumé}

Il y a eu depuis la moitié du XXe siècle une prolifération d'études sur divers champs de la connaissance de la région des Guyanes. Cependant, il persiste aujourd' hui une grande lacune dans l'actualisation de la cartographie thématique qui explique ses géographies. Notre objectif est de lancer des réflexions sur l'élaboration de 5 cartes destinées à mettre en évidence les aspects de l'aménagement du territoire de cette région, et, ainsi, de traiter des questions importantes relatives au passé et au présent des Guyanes. Pour composer les cartes et nos arguments nous avons recouru à des lectures, à la collecte et la quantification de données primaires (statistiques) et à des études de terrain comme bases méthodologiques.

Mots-clés: Géographie Régionale. Région des Guyanes. Études de terrain. Cartographie.

\section{Introdução}

As Guianas, região ainda pouco conhecida e estudada da Amazônia internacional, já passou por muitas transformações territoriais desde que seus primeiros habitantes, os indígenas, povoaram-na há mais de 10 mil anos (Eriksen, 2011). Com a chegada dos exploradores europeus desde o final do século XV, ou seja, apenas meio milênio atrás, seguido por africanos escravizados nos séculos XVI e XVII, dos asiáticos e de povos do próprio continente americano nos séculos XIX e XX, ocorreu um longo processo de ocupação, circulação e construção de territorialidades nas Guianas, resultando numa região complexa sob diversos aspectos sociais, econômicos, políticos e geopolíticos. Ademais, fato relevante é que ainda persiste uma significativa carência de cartografias temáticas que deem suporte à explicação da geografia regional do passado e do presente. Neste texto, contribuímos com a superação dessa lacuna a partir de cinco mapas representativos do contexto regional, além de um mapa introdutório, que é o primeiro a ser exposto, no qual mostramos a localização e as unidades administrativas.

\section{O recorte regional}

Nosso foco é a região das Guianas, uma vasta área entre os rios Orinoco e Amazonas, margeada pelo oceano Atlântico (Mapa 1). Dois trabalhos foram os pilares para nossa regionalização: Os livros de Lézy (2000) e de Hammond (2005). São atribuídos ao britânico Walter Raleigh os primeiros relatos de parte da rica natureza das Guianas em The Discovery of Guiana (Raleigh, 1596), escrito um ano após sua primeira expedição à Amazônia. Três séculos depois, em 1895, Elisée Reclus analisou a região das Guianas por seus aspectos 
naturais (tamanho, forma e localização) em seu famoso livro Geografia Universal. Pouco depois, no início do século XX, Vidal de La Blache também fez uma leitura da região, mas agora por aspectos históricos e cartográficos. Ele observou que havia uma grande sintonia paisagística na macrorregião cujas bordas são o Orinoco e o Amazonas ao analisar mapas antigos da América do Sul (Lézy, 2000). Mesmo assim, diríamos que foi a partir da década de 1950 que numerosos textos foram publicados sobre a região das Guianas em diferentes campos de conhecimento (Hammond, 2005), suscitando - já no novo século - no surgimento de grupos de pesquisadores destinados a avaliar aspectos históricos, geográficos e antropológicos da região que aqui pomos em destaque.

Tanto Lézy (2000) quanto Hammond (2005) colocaram em evidência várias cartografias sobre as Guianas, mas ainda assim os mapas aqui expostos avançam em refinamento e atualização (Mapas 2 e 3) e na inovação com mapas complexos do ponto de vista da elaboração e da aquisição de dados válidos para todos os países das Guianas em perspectiva comparada (Mapas 4 a 6).

\section{Mapa 1 - Área administrativa da região das Guianas}

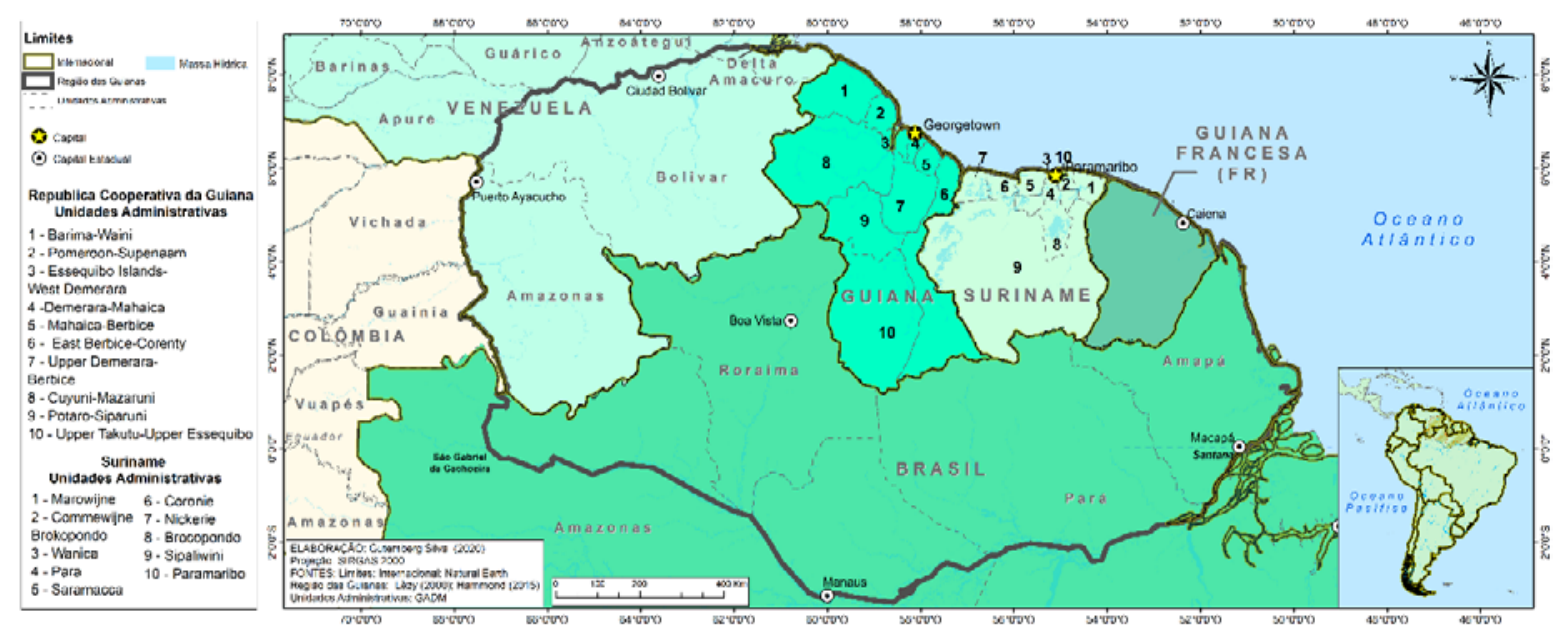

\section{Os dados utilizados}

Para montagem dos cinco mapas a seguir foram utilizados dados primários (último Censo de cada país); bases espaciais internacionais que contemplassem toda a área de estudo; revisão de literatura; e trabalho de campo, este último realizado entre janeiro e fevereiro de $2020{ }^{2}$ Para representação cartográfica utilizamos o programa ArcGis 10.1. Em alguns mapas, acrescentamos fotos do trabalho de campo para ilustrar as representações cartográficas.

\section{A metodologia/criação dos mapas e sua breve discussão}

O Mapa 2 foi criado essencialmente cruzando-se informações de Lézy (2000), Tavares (2011) e Eriksen (2011). Ele traz duas cartografias: a maior apresenta três informações fundamentais: (i) a distribuição dos povos indígenas na região das Guianas no momento do contato com europeus, (ii) uma hipótese da localização do Eldorado, cidade mítica obsessivamente

2 Ao longo de 20 dias, o autor percorreu por terra todo o trajeto da transrodoguianense (exceto entre Santa Elena e Ciudad Guayana, na Venezuela) e, em seguida, o eixo fluvial Manaus-Santana pelo rio Amazonas (Mapa 4). 
procurada no período colonial na Amazônia, e (iii) a rota dos exploradores europeus nos séculos XVI e XVII. Há ainda uma cartografia menor, que mostra o território explorado pelos europeus na Amazônia internacional e os dois principais dispositivos de divisão territorial de grande impacto na formação territorial das Guianas, os Tratados de Tordesilhas (1492) e de Madrid (1750). Com raras exceções, as explorações pelas bordas da região tiveram impacto muito forte no ordenamento regional, pois até hoje todo o processo de ocupação demográfica e montagem das bases centrais do sistema de engenharia da região ocorrem essencialmente pelas bordas das Guianas (Mapas 5 e 6), justamente onde estão as principais cidades.

\section{Mapa 2 - Povos indígenas e primeiras explorações na região das Guianas}

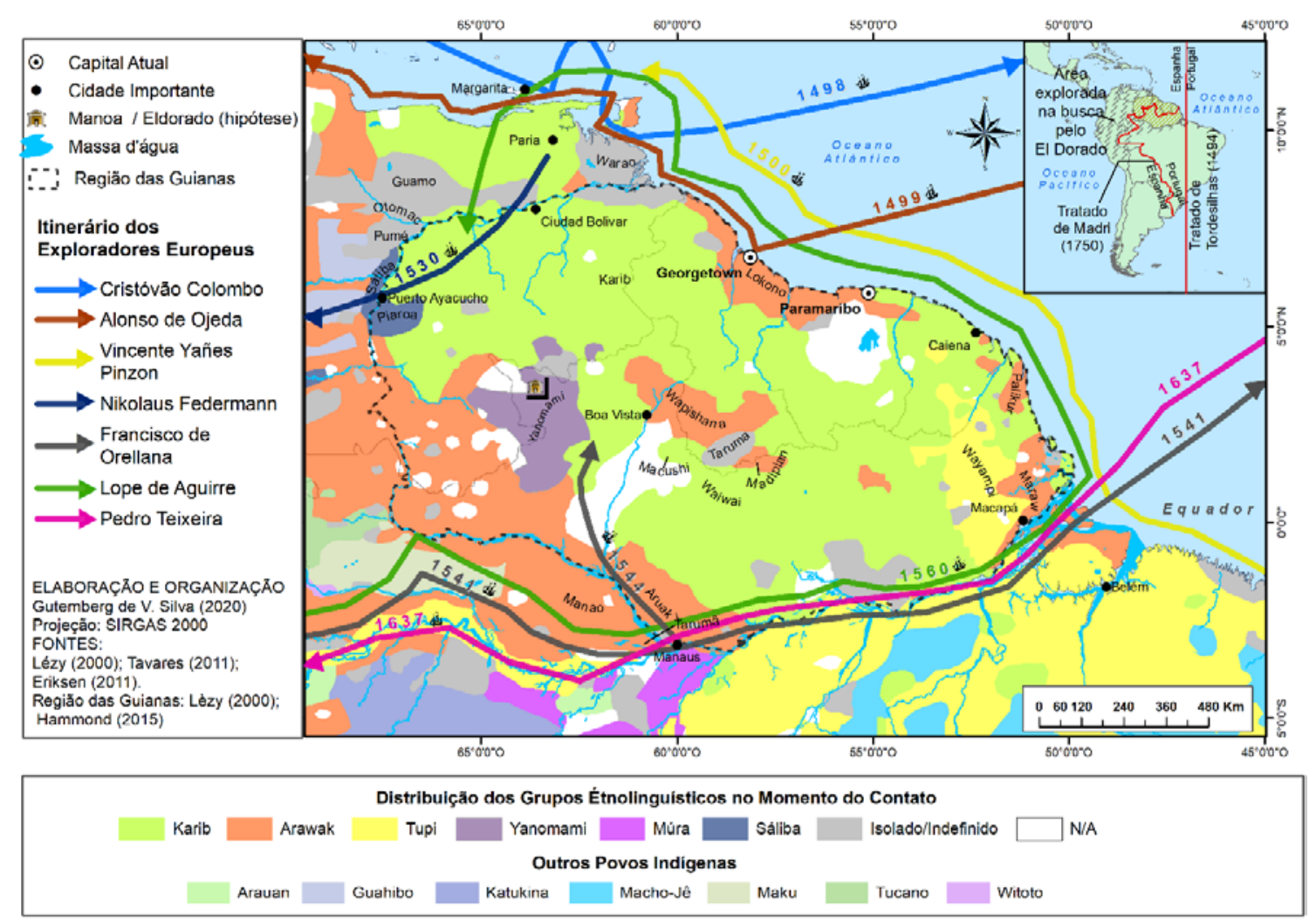

O Mapa 3 foi criado a partir de uma vasta revisão de literatura sintetizada principalmente por Silva (2017), mas também com base em outros referenciais mencionados no mapa. Nele apresentamos litígios resolvidos e aqueles que ainda podem causar constrangimentos diplomáticos e até resultar em eventuais conflitos armados. Embora se apontem sempre vários fatores para novos embates e necessidades de intervenção diplomática, as riquezas minerais - ouro e diamante no continente e petróleo na Zona Econômica Exclusiva (ZEE), sempre determinaram a geopolítica das fronteiras na região (Silva, 2017, 2020), o que torna esse mapa relevante para uma análise global dos litígios lá existentes. 


\section{Mapa 3 - Ordenamento territorial/disputas fronteiriças das Guianas}

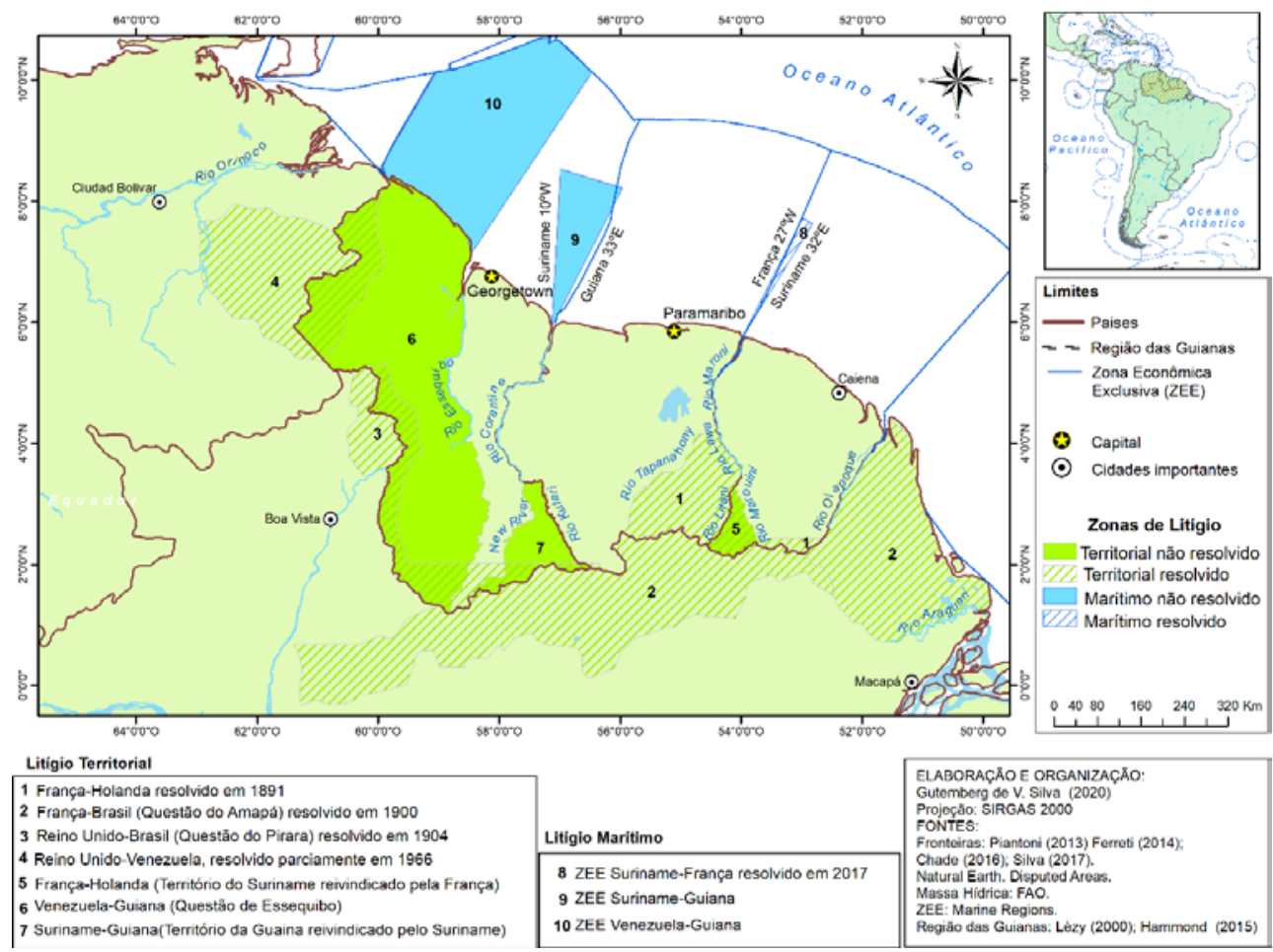

Mapa 4 foi elaborado com base em trabalho de campo e suporte do Open Street Map (2021) para mostrar os padrões dos pares de cidades de fronteira da região das Guianas. Não conseguimos padronizar a escala para as cidades em razão do tamanho e distância entre elas. No conjunto, são 5 pares dos quais quatro são fronteiras naturais e uma é fronteira seca. Das primeiras, três delas estão na foz do rio onde se encontram, conferindo-lhes relevante posição estratégica para entrada e saída da região.

\section{Mapa 4 - Cidades fronteiriças na região das Guianas}

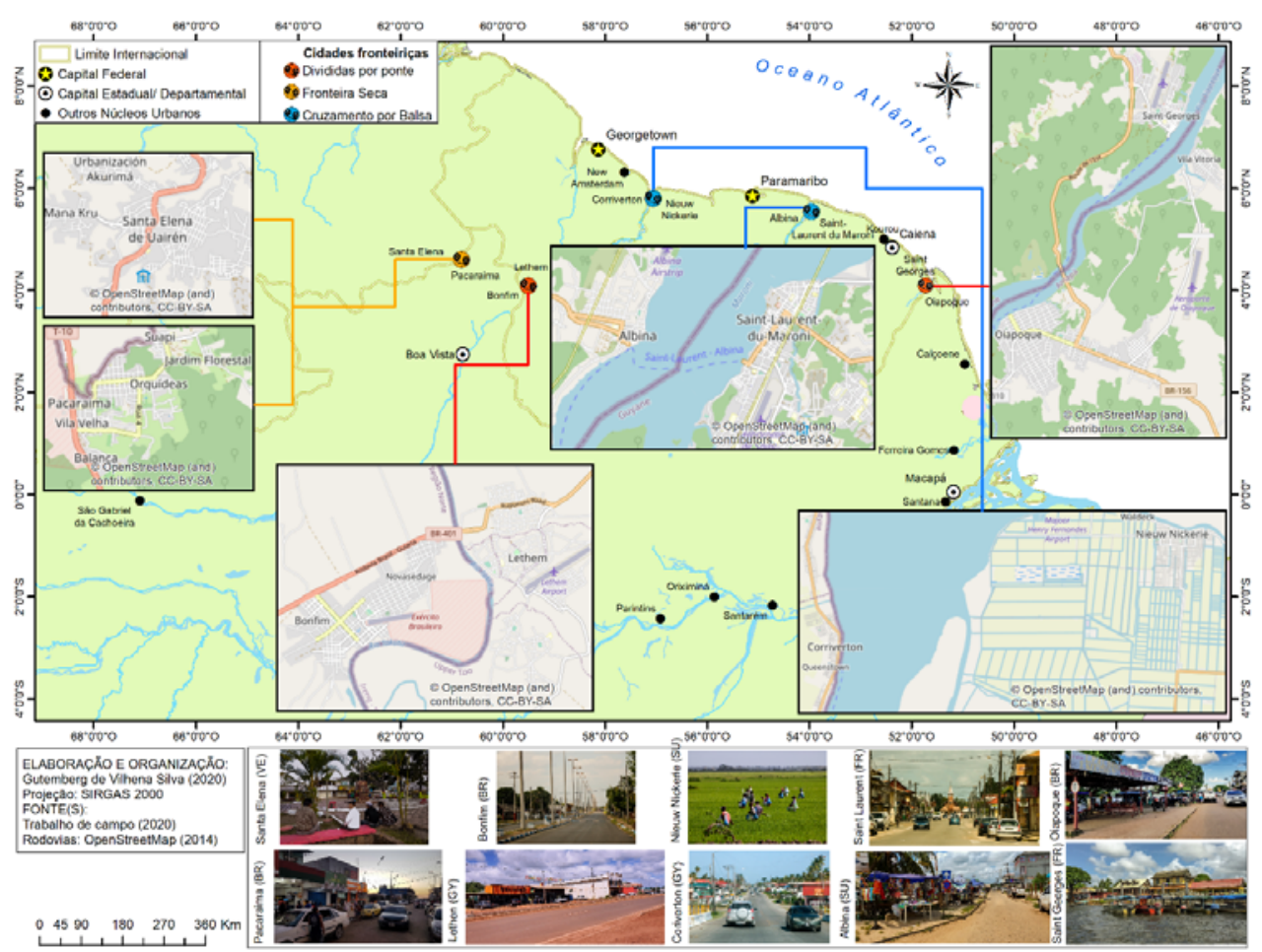


O Mapa 5 foi construído essencialmente a partir de dados dos últimos Censos de cada país e do trabalho de campo realizado. Para agregação dos dados, na Venezuela e no Brasil utilizamos as divisões municipais. Na República da Guiana, as suas regiões administrativas. $\mathrm{Na}$ Guiana Francesa foram utilizadas as comunas e no Suriname os seus distritos. Após esta demorada etapa, conseguimos expor a distribuição da população na cartografia maior do mapa em questão, demonstrando a grande concentração demográfica em cidades das bordas da região. Há ainda outras cinco representações cartográficas menores: uma é de localização e as demais, de alguns dos principais grupos étnicos representativos da região das Guianas: os indígenas, representados por suas áreas, demarcadas ou não (RAISG, 2019); os garimpeiros, em geral brasileiros, os Bushnengués, grupo muito peculiar de origem africana que se capilarizou pela fronteira guiano-surinamesa; os indianos, chineses e javaneses que chegaram desde meados do século XIX para suprir carências de trabalho; e, por fim, os hmongs, grupo ético que aportou na Guiana Francesa na década de 1970 com a crise da Indochina.

\section{Mapa 5 - Demografia da região das Guianas}
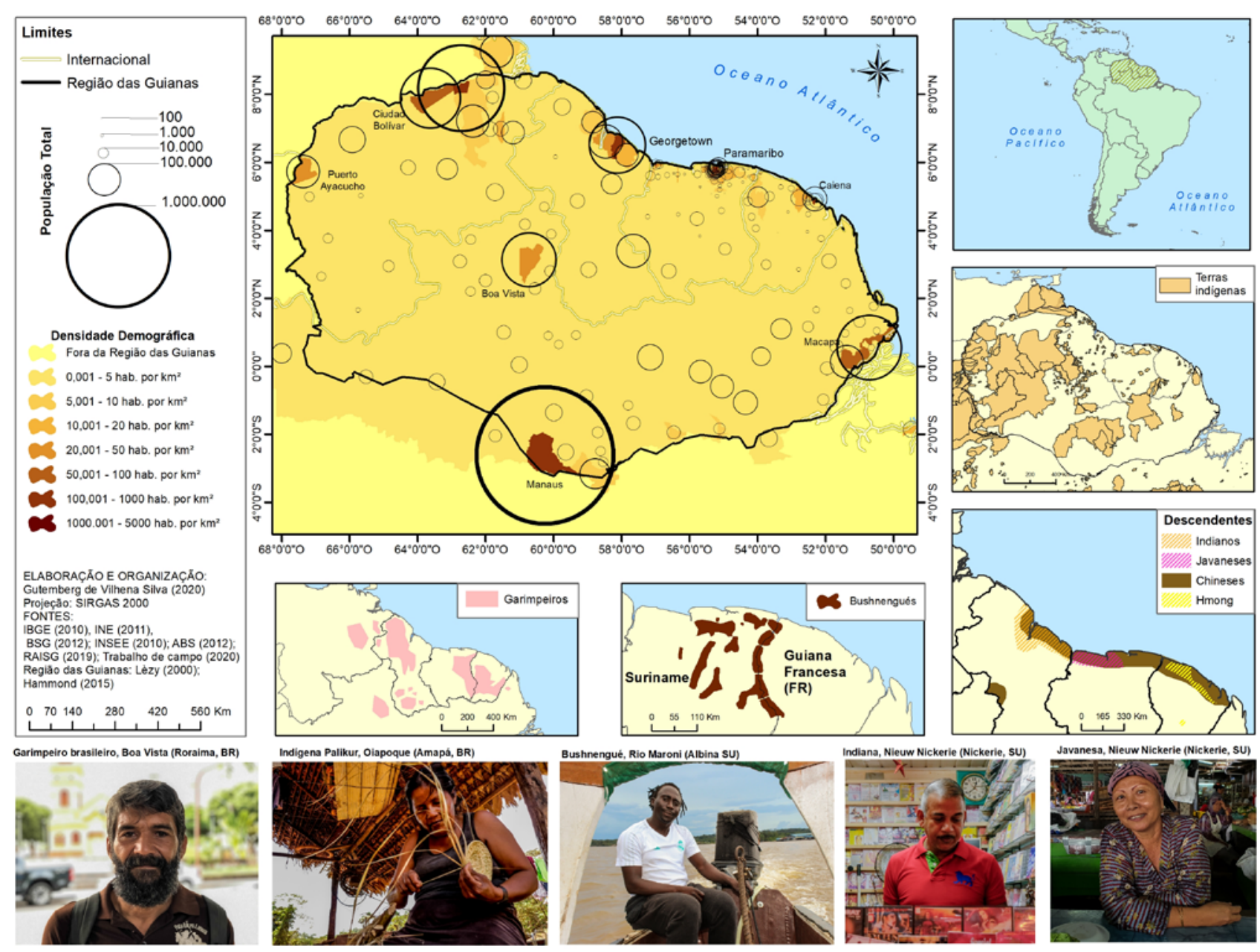

Mapa 6 mostra o sistema de engenharia montado na região das Guianas. A cartografia foi construída após vasta consulta de informações sobre portos, aeroportos, ferrovias, hidrovias, revisão de literatura e trabalho de campo. Essa representação põe em evidência a escolha dos padrões de circulação e conexão no conjunto regional. Hoje, a rede multimodal da região das 
Guianas é formada por variadas conexões fluviais, poucas rotas rodoviárias, alguns voos regulares intra e inter-regionais e uma base ferroviária quase inexistente. Podemos dividir sua estrutura logística em três grandes eixos: (i) na faixa litorânea atlântica predominam as rodovias, (ii) no grande arco entre os rios Orinoco e Amazonas - e penetrando a floresta em todos os sentidos, as hidrovias, e (iii) no grande interior regional, os aviões, em geral de pequeno porte, e as canoas, com ou sem motor de popa, quase sempre pilotadas pelas populações tradicionais.

\section{Mapa 6 - Estrutura logística da região das Guianas}

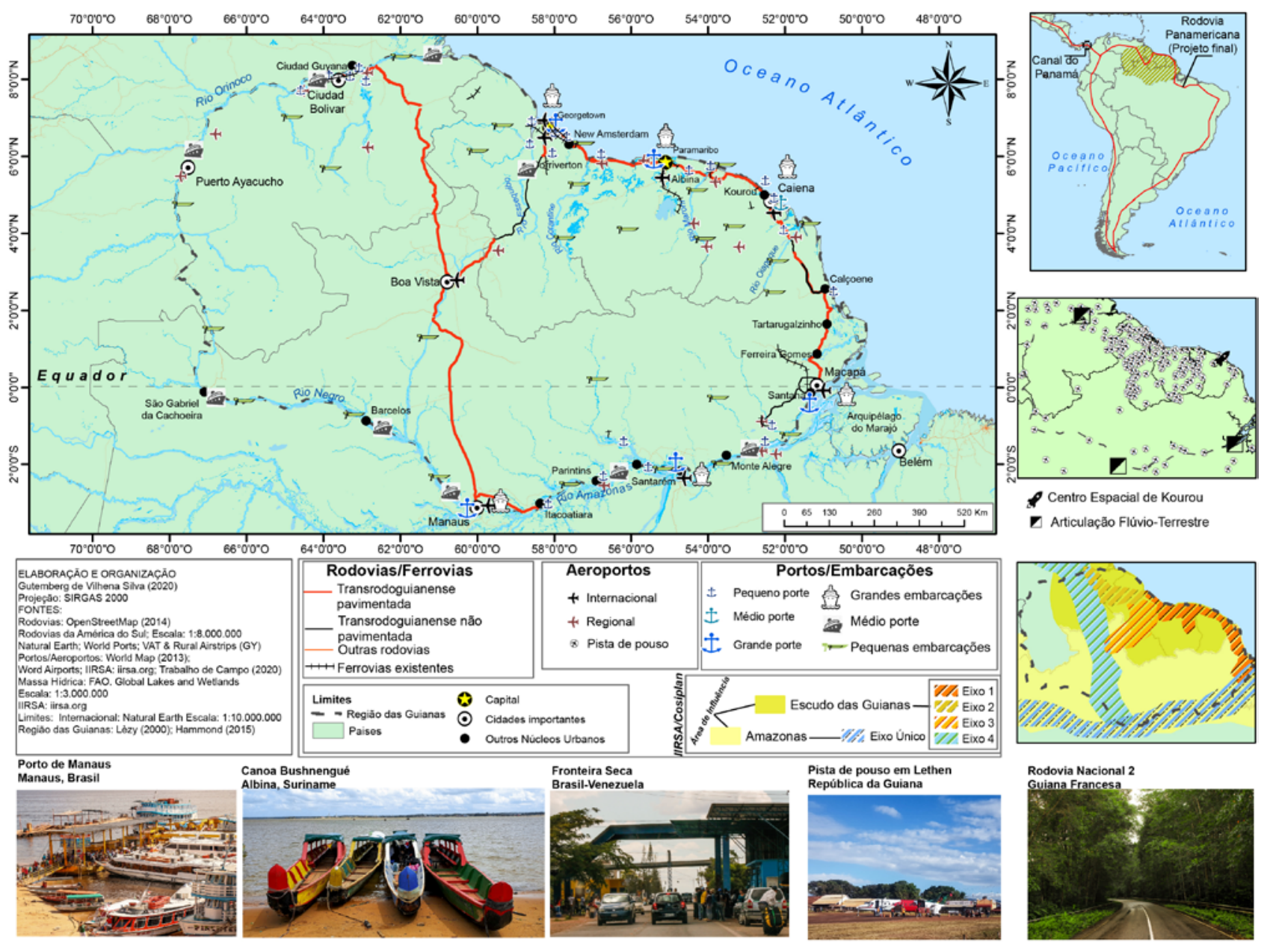

\section{Conclusão}

Todos originais na construção e a maior parte de concepção inovadora, os mapas ajudaram-nos a avançar no entendimento do ordenamento territorial das Guianas, resultado de um rico e complexo processo histórico de ocupação e demarcação de territórios, das opções de montagem do sistema de engenharia da região e dos ainda vivos e tensos litígios por fronteiras, que se refletem nas interações entre as cidades limítrofes. A cartografia também evidenciou uma população concentrada nas bordas, mas um litoral, embora fraco em densidade, rico em comunidades tradicionais. 


\section{Referências}

ABS. Algemeen Bureau voor de Statistiek. Censo Demográfico do Suriname, 2012. Disponivel em: https://statistics-suriname.org/nl/. Acesso em: 6 jun. 2021.

BSG. Bureau of Statistics of Guyana. Censo Demográfico da República da Guiana, 2012. Disponível em: https://statisticsguyana.gov.gy/. Acesso em: 6 jun. 2021.

CHADE, J. Mapa inédito revê disputa pela região do Amapá. O Estado de S. Paulo, São Paulo,

18 dez. 2016. Disponível em: https://brasil.estadao.com.br/noticias/geral,mapainedito-reve-disputa-pela-regiao-do-amapa,10000095231. Acesso em: 6 jun. 2021.

ERIKSEN, L. Nature and Culture in Prehistoric Amazonia: Using GIS to reconstruct ancient ethnogenetic processes from archaeology, linguistics, geography, and ethnohistory. Lund, SE: Human Ecology Division/Lund University, 2011. Disponível em: https://lup.lub. lu.se/search/ws/files/3626162/1890749.pdf. Acesso em: 6 jun. 2021.

FERRETTI, F. Pierre Deffontaines et les missions universitaires françaises au Brésil: enjeux politiques et pédagogiques d'une société savante outremer (1934-1938). Cybergeo, 2014. doi: https://doi.org/10.4000/cybergeo.26645.

HAMMOND, D. S. (org.). Tropical Forests of the Guiana Shield: Ancient Forests in a Modern World. Oxfordshire, GB: CAB International, 2005.

IBGE. INSTITUTO BRASILEIRO DE GEOGRAFIA E ESTATÍSTICA. Dados do Censo Demográfico, 2010. Disponível em: https://www.ibge.gov.br/. Acesso em: 6 jun. 2021.

INE. INSTITUTO NACIONAL DE ESTATÍSTICA. Censo Demográfico da Venezuela, 2011. Disponível em: http://www.ine.gov.ve/. Acesso em: 6 jun. 2021.

INSEE. INSTITUT NATIONAL DE LA STATISTIQUE ET DES ETUDES ECONOMIQUES. Censo Demográfico da Guiana Francesa, 2010. Disponível em: https://insee.fr/fr/accueil. Acesso em: 6 jun. 2021.

LÉZY, E. Guyane Guyanes, une géographie "sauvage" de l'Orénoque à l'Amazone. Paris: Belin, 2000.

OPEN STREET MAP. State of the map. 2021. Disponível em: https://www.openstreetmap. org/\#map=2/2.8/-97.4. Acesso em: 6 jun. 2021.

PIANTONI, F. Mapa das disputas marítimo-territoriais da região das Guianas, 2013. Não publicado.

RAISG. REDE AMAZÔNICA DE INFORMAÇÃO SOCIOAMBIENTAL GEOREFERENCIADA. Terras indígenas, 2019. Disponível em: https://www. amazoniasocioambiental.org/pt-br/. Acesso em: 6 jun. 2021.

RALEIGH, W. The discoverie of the large, rich and beautiful Empyre of Guiana. London: World Publishing Company, 1596. 
SILVA, G. V. Des frontières contestées: les conflits des Guyanes. In: NOUCHER, M.; POLIDORI, L. (dir.). Atlas Critique de la Guyane, CNRS, 2020. p. 48-49.

SILVA, G. V. Litiges transfrontaliers sur le plateau des Guyanes, enjeux géopolitiques à l' interface des mondes amazoniens et caribéens. L'Espace Politique, v. 31, n. 1, 2017. doi: https://doi.org/10.4000/espacepolitique.4242.

TAVARES, M. G. A Amazônia brasileira: formação histórico-territorial e perspectivas para o século XXI. Geousp, São Paulo, v. 15, n. 2, p. 107-121, 2011. doi: https://doi. org/10.11606/issn.2179-0892.geousp.2011.74209.

Recebido em: 22 set. 2020

Aprovado em: 22 dez. 2020 